\title{
The Lonelier, the More Conservative? A Research about Loneliness and Risky Decision-Making
}

\author{
Yu Zhu, Chen Wang* \\ Jinan University, Guangzhou, China \\ Email: * chenw ang@stu2015.jnu.edu.cn
}

How to cite this paper: Zhu, Y., \& Wang, C. (2017). The Lonelier, the More Conservative? A Research about Loneliness and Risky Decision-Making. Psychology, 8, 1570-1585.

https://doi.org/10.4236/psych.2017.810104

Received: July 25, 2017

Accepted: August 21, 2017

Published: August 24, 2017

Copyright () 2017 by authors and Scientific Research Publishing Inc. This work is licensed under the Creative Commons Attribution International License (CC BY 4.0).

http://creativecommons.org/licenses/by/4.0/

(c) (i) Open Access

\begin{abstract}
Mountings of studies discussed about a variety of antecedent factors of risky decision making, however, loneliness, as a vital psychological state featured by affection, cognition as well as behavior, was seldom connected to risky decision-making. The current study aims to figure out whether loneliness would influence decision making under risks and the possible underlying mechanism. Two hundred and fifty participants attended our studies and completed gambling games via either pen-paper or E-Prime software. The results indicate that higher level of loneliness predicts less perceived self-control, which in turn leads to a tendency to avoid risks. However, this effect is only significant in gain scenarios rather than loss scenarios, suggesting there might exist an interaction between loneliness and condition factor. Our findings contribute to previous research by verifying that the preventive focused mind-set of loners can go beyond social events and influences decision making behaviors.
\end{abstract}

\section{Keywords}

Loneliness, Decision-Making, Risk Preference, Perceived Self-Control

\section{Introduction}

Decision making under risks is a topic that has attracted substantial body of studies. Many investigations and experiments indicated that individuals' preference towards uncertainties depends on not only the given situations (Wegier \& Spaniol, 2015; Buckert, Schwieren, Kudielka, \& Fiebach, 2014), but also individual differences such as personal traits (Byrne, Silasi-Mansat, \& Worthy, 2015; Xiu, Kang, \& Roline, 2015), emotional arousing (Cassotti et al., 2012; De Martino, Camerer, \& Adolphs, 2010) and cognitive processes (Blanchette \& Richards, 
2010; Dohmen, Falk, Huffman, \& Sunde, 2010). However, to our surprise, loneliness, as a psychological experience that leads to extensive outcomes including affection (Kearns, Whiteley, \& Ellaway, 2015; Dohle, Keller, \& Siegrist, 2012), cognition (Otten \& Jonas, 2013; Cacioppo \& Hawkley, 2009; Baumeister, Twenge, \& Nuss, 2002) as well as behavioral tendencies (Cotten, Anderson, \& McCullough, 2013), was rarely taken account into the research of decision making. Therefore, in this case, we attempt to examine whether lonely people would behave differently from non-lonely people in monetary decision making tasks and the possible underlying pathway.

Loneliness refers to a painful mental experience when people perceive the present social contacts could not meet their expectations (Peplau \& Perlman, 1982), which depends on the perception of social quality rather than the object social isolation. According to Heinrich and Gullone's (2006) point, loneliness is a complicated state that contains both emotional and cognitive elements. Whereas it would represent depressive emotions and impaired cognition (Jaremka et al., 2014; Hawkley \& Cacioppo, 2010), loneliness is basically thought to benefit for species survivals (Masi, Chen, Hawkely, \& Cacioppo, 2013; Heinrich \& Gullone, 2006). During the long history of human beings, individuals have to rely on each other, for example, children obtain care from parents, tribe members share food and labor tools. Namely, loneliness plays a vital role to facilitate individuals to stay together and protect against external perils, which could also interpret why those who feel excluded are more sensitive to threatening cues (Masi et al., 2013; Hawkley \& Cacioppo, 2010; Vohs, Baumeister, \& Chin, 2007). In addition, experimental evidences also found that isolation or rejection would result in dysfunction of hippocampus and prefrontal cortex or overreactions of neural system (Will et al., 2016; Silva-Gomez et al., 2003), which reflected a certain adaption of persistent hyper vigilance on isolated individuals. Accordingly, the feeling of loneliness is able to strengthen the perception of fear provoking cues and lead to a preventive focused mind-set (Lucas et al., 2010). As has been noted in regulatory focused theory, individuals would be motivated to do things they "feel right about", hence, those who aim to seek safety and minimize potential loss would probably stay in preventive orientation towards uncertainties (Higgins, 1997).

So far, a massive amount of research validated the preventive orientation of lonely individuals (Derfler-Rozin, Pillutla, \& Thau, 2010; Lakin, Chartrand, \& Arkin, 2008). For example, although lonely people desire to repair negative feelings and rebuild social contacts, many of them fail due to the overcautious strategies towards social activities (Masi et al., 2013; Lucas, Knowles, Gardner, Molden, \& Jefferis, 2010). In other word, they are more concerned to prevent against being rejected, even at the risk of staying isolated. Moreover, a higher frequency of social network site usage among loners has been observed (Teppers, Luyckx, Klimstra, \& Goossens, 2014; Cotten et al., 2013; Clayton, Osborne, Miller, \& Oberle, 2013), supporting that comparing to face-to-face interactions which contain more indeterminacy, lonely people prefer online relationships for the sake of 
minimizing anxiety. In addition, more recently, a few researchers caught sight of the passive attitude of loners in workplace and found employees who feel social supports unsatisfying are usually less engaged in work and produce poorer task performances due to the excessive worries (Snyder, 2014; Lam \& Lau, 2012). Taken prior literature together, the consensus appeared to be that lonely people are generally described as overcautious, less vigor and risk-evading. This line of research demonstrated that people high in loneliness are more preventive oriented, however, a diminished response went beyond social events. Hence, little is known whether similar tendency could be generalized to other aspects, for example, risky decision making. How would loners react when faced with uncertain conditions? Therefore, we aimed to fill this gap by examining whether the conservative orientation would be consistent with social performance in the context of gambling tasks.

Additionally, in despite of the paucity of reports that connect loneliness with monetary decisions, Pieters (2013) pointed out that loneliness and materialism are notable lined to each other, suggesting that lonely people might be particularly germane to material possessions such as money. Specifically, previous studies widely accepted that the belief in materialism would harm personality interactions due to the conflicts between self-centered world view of materialists and social values. Generally, when someone focuses more on self-enhancement like power, wealth and personal achievements, the importance of human relatedness would be underestimated (Bauer, Wilkie, Kim, \& Bodenhausen, 2012; Van Boven, Campbell, \& Gilovich 2010). As such, materialists tend to deactivate benevolent behavior and social activities, which may thus thwart attachments with others. Meanwhile, the unpleasant lonely feelings would steer individuals toward over-reliance on material belongings conversely to get rid of social insecurity (Pieters, 2013; Sheldon \& Kasser 2008). Likewise, Lastovicka and Sirianni (2011) also proposed that when people experience grievous social events and try to cast off negative feelings, they would turn to material possessions like money as compensation. Therefore, if it is true that there exists the reciprocal influence between loneliness and materialism, then a frustrating social relatedness might affect one's attitude towards financial risks. As existing evidences suggest, lonely individuals may less likely to take the risk of losing money they already get for uncertain returns.

Besides, another aim of our study is to delve into through which pathway that loneliness could influence risk preference during monetary decision tasks, specifically, we assumed that perception of self-control would possibly plays a bridge role considering its significant relevance to both loneliness and decision making. Perception of control is usually defined as a belief of how much people can control themselves and alter events (Skinner, 1996), which is a robust cognitive predictor of a variety of mental and behavioral outcomes. Several lines of studies considered that individuals with high level of loneliness usually described as hopeless, self-contemptuous and anxious, tending to blame external factors when something negative occurs (Ye \& Lin, 2015; Heidemeier \& Göritz, 2013; 
Trope, Gervey, \& Bolger, 2003), suggesting that lonely people are less likely to believe they are able to affect things. Also, it has been proved that lonely people are easier to be addicted to cigarettes and alcohol because they perceive incapable to control themselves (Hawkley \& Cacioppo, 2010). Moreover, prior theory and experiments validated that the extent of control feelings is the result of previous experiences (Martinez et al., 2011; Sun, 2011). Via giving positive feedback, researchers could effectively increase participants' perceived control while negative feedback could create the opposite outcome. Hence, the negative experience of social events and low self-evaluation of lonely people would possibly explain their loss of perceived control. In other word, regardless the objective social interactions, lonely individuals always perceive that they are being or will be rejected by others, which makes them feel self-contemptuous. More importantly, previous studies suggested that perceived self-control might play a vital role between loneliness and social deficiency. In contrast from some early hypotheses, both being excluded and fear of being excluded increase attention to facial and vocal expressions, thus, lonely individuals are better at understanding social signals as well as emotions of others (Cheung \& Gardner, 2015; Sacco, Wirth, Hugenberg, Chen, \& Williams, 2011), so the underperformance in social activities more likely stems from cognitive problems rather than a lack of ability. Accordingly, Lucas et al. (2010) explained the poor social condition of loners based on the excessive fear of negative evaluation and extreme loss of confidence.

On the other hand, it should be noted that perceived self-control is also accepted as a major influential factor in the case of decision making domain. Since long time ago, researchers started to notice that manipulating an illusion of control is able to significantly increase risk choices during gambling games because participants tend to be over optimistic when they perceive risks are under control (Martinez et al., 2011; Nordgren, Joop, \& Van Harreveld, 2007). In addition, Sun (2011) demonstrated that locus of control is also closely connected to information processes, which in turn affects purchasing decisions. Individuals with external locus of control, namely, the feeling of uncontrollability would make people more susceptible to external influences and causing a larger endowment effect, suggesting that they may own intensive "loss aversion". Hereto, regulatory focus theory (Higgins, 1997) may able to offer a good explication by distinguishing the basic approach motivation systems. Based on the theory, individual's regulatory orientation comes from the underlying motivations. Those who attempt to seek security would be preventive focused while those who aim to maximize benefit would tend to be promotive. Meanwhile, the perception of control is actually thought to be part of motivation system that stimulates individuals to stay in either preventive or promotive mind-set (Greenaway et al., 2015; Heidemeier \& Göritz, 2013). Consequently, we expected that low level of perceived self-control would lead to a security seeking oriented motivation and tend to avoid expected loss.

To reiterate, the purpose of our study is to examine whether loneliness is able to influence the risk preference in monetary decision making tasks as well as the 
possible mediation role of perceived self-control. In order to assess the risk preference, we adopted Saqib \& Chan's (2015) gambling game, utilized monetary trials under either gain or loss condition, so that we can examine the effect of loneliness in different conditions. During each trial, participants had to select from a risky option and a safe one so that we could examine which option was favored by loners. Build on previous research and theory, we expected that lonely participants would perceive lower level of perceived self-control, which in turn would lead to a preference towards safe options, and non-lonely participants would be the opposite. Although our predication is based on a relatively straightforward existing research, the novelty of this research is to go beyond social events and test the lonely feeling's impact on economic decision making performance, which has not been addressed before. Also, we made another contribution by figuring out the underlying cognitive factor, suggesting the possibility of other behavioral outcomes of loneliness.

\section{Study 1}

The purpose of study 1 was to examine the overall relationship between loneliness and risky decision making performance. We adopted a gambling game which contains scenarios over gains as well as over loss (within-subjects), which is one of the most commonly used paradigms to examine risk preference. Each trial contains a safe choice and a risky choice, participants were asked to choose the one they prefer. Meanwhile, we divided participants into low-loneliness group and high-loneliness group according to their UCLA scores. This resulted in a 2 (loneliness: low, high) $\times 2$ (condition: gain, lose) mixed design.

\subsection{Method}

\subsubsection{Participants}

A total of 105 undergraduate and postgraduate students were recruited from an university in the south of China, none of them attended similar research tasks. In order to exclude possible extraneous variables, we asked all students to self-report about their personal interactions, to make sure no participant experienced extremely negative social events (for example, being excluded by classmates, losing a close family member) during the last two years. Therefore, all participants own at least an average degree of social life but varied in the feelings of loneliness. 12 invalid questionnaires were excluded due to incomplete data, resulting in a total of 93 valid questionnaires (30 males, 63 females; $\mathrm{M}_{\text {age }}=22.04, \mathrm{SD}_{\text {age }}=2.03$ ).

\subsubsection{Measures}

\section{1) R-UCLA loneliness scale}

The R-UCLA is the most widely used scale to test perceived levels of lonely feelings and the degree of satisfaction with one's personal interaction. It has been confirmed to have excellent reliability and validity (Russell, Peplau, \& Curtrona, 1980). A research of Cacioppo \& Patrick (2008) indicated that even a short term with as short as three items can still show nomological validity. In our research, 
we used short-form versions with ten items (Pieters, 2013). Example items include "there is no one I can turn to", "I feel left out". Response categories were 1 (never), 2 (seldom), 3 (regularly), and 4 (often). However, we deleted item 5 ("I can find companionship when I want to") due to the lack of reliability. After reverse scoring two items, loneliness scores were calculated by summing the rest of eight items. A higher of the score indicates a higher level of loneliness. The Cronbach's alpha in our research was ranging from .743 to .805 .

\section{2) Risk preference}

To measure risk preference, we asked participants to complete a gambling game adapted from Saqib \& Chan (2015). Participants were given two scenarios (condition: gain, loss) and each scenario contains 28 trials. On a given trial, participants must decide a preferred one between a safe choice and a risky choice. The safe choice refers to winning or losing some money with certainty; while the risky choice refers to winning or losing money with .5 probabilities (or else nothing). The difference of expected value between both choices changes gradually. We computed risk preference by counting the number of risky choices. A higher score was associated with a stronger tendency to take risks. Every participant must complete all trials under both conditions, making it a within-subjects factor.

\subsubsection{Procedure}

All participants completed decision-making task and UCLA Loneliness Scale individually in the library or a classroom via pen-paper. The instructions of both scenarios are as follows:

\section{Gain condition}

Imagine that you won a lottery and now you are faced with two choices to receive the reward. Choice $A$ is to receive a small amount of money immediately. Choice $B$ is to take part in another lottery, you will have .5 probabilities to gain more money but .5 probabilities to lose money you already got. You have to and can only choose either $A$ or $B$. Which one do you prefer?

\section{Loss condition}

Imagine that you broke public property unconditionally and now you are faced with two choices to deal with it. Choice $A$ is to pay a small amount of fine. Choice $B$ is to complain and you will have .5 probabilities to be off the fine but .5 probabilities to pay more money. You have to and can only choose either $A$ or $B$. Which one do you prefer?

Participants were asked to finish gain scenario first and then the loss scenario, between the two conditions they were given a two-minute break. After this task, participants needed to answer the question "how difficult did $u$ feel to make a decision during the task?" score ranges from 1 ("extremely difficult") to 5 ("extremely easy"). Finally, participants were asked to report demography information such as gender, age, education.

When all measures were done, we divided participants into low-loneliness group $(\mathrm{N}=46)$ and high-loneliness group $(\mathrm{N}=47)$ based on their UCLA scores, 
hence, no participant knew which group they belong to during the task. One week later, we informed participants their results and our gratitude for their support.

\subsection{Results}

We divided all participants into low-loneliness group $(\mathrm{N}=46, \mathrm{M}=17.13, \mathrm{SD}=$ 2.06) and high-loneliness group $(\mathrm{N}=47, \mathrm{M}=22.38, \mathrm{SD}=2.83)$ based on UCLA scores. Independent $\mathrm{t}$ tests indicated that the extent of lonely feelings of two groups were remarkably different, $p<.01$. Meanwhile, individuals in both loneliness groups showed no difference in post-task question, $p>.10$.

Next, another independent $t$ test was conformed to examine the decision making performance in both loneliness groups and the results were shown in Figure 1. As expected, when under the gain condition, participants with higher UCLA scores showed more tendencies to avoid risks than those with lower UCLA score $(\mathrm{t}=2.91, p<.01, \mathrm{~d}=4.19)$. However, the difference between two groups under loss condition had not reach significance $(\mathrm{t}=-.656, p>.10, \mathrm{~d}=$ 1.05).

Then, an ANOVA test reexamined the relationship between loneliness and risk preference under both conditions. The main effect of loneliness on the numbers of risky choices in gain scenario $\mathrm{F}(1,91)=8.408, p<.01, \eta^{2}=.09$ was significant while in loss scenario it became indistinctive $\mathrm{F}(1,91)=.43, p>.10$. $\eta^{2}=.01$. That means the effect of loneliness might be moderated by the condition set. Additionally, we also found the main effect of condition was statistically significant $\mathrm{F}(1,184)=16.61, p<.01, \eta^{2}=.08$, showing that participants selected far more risky choices in gain scenario than in loss scenario.

\subsection{Discussion}

Study 1 indicates the significant inverse relationship between loneliness and risk preference under gain condition, participants with higher level of loneliness preferred safe choices than those with lower level of loneliness. However, not conformed to what we supposed, although participants in high loneliness group still indicated more risk-aversion than when faced with monetary loss, the

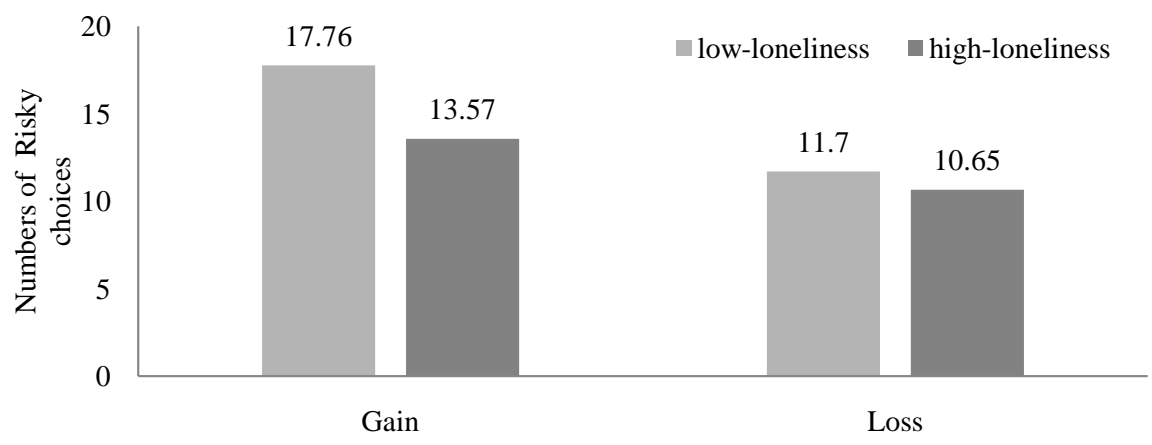

Figure 1. Risk preference of two groups in Study 1. 
difference between two groups was highly diminished, which suggests there might exist an interaction between loneliness and the condition factor.

We then attributed the results to two possible reasons. First, as discussed above, participants took less risk under loss condition than gain condition might because of the loss aversion. That is to say, when participants expected negative outcomes, a non-lonely one may turn to be preventive like a lonely one and reluctant to increase the possibility to lose more. Second, the indistinct difference may hail from the inaccurate measures, because all trials were presented on paper, we couldn't random the sequence of trials, which may have skewed the results. Moreover, choices in both scenarios might affect each other. Therefore, we designed study 2 to replicate our findings as well as further verify the possible mediation role of perceived self-control.

\section{Study 2}

In order to reexamine the main effect of loneliness on risky decision-making under both gain and loss conditions as well as measuring the mediation role of perceived self-control between loneliness and risk preference, we conducted study 2 on PC computers using E-Prime 2.0 software.

\subsection{Method}

\subsubsection{Participants}

145 undergraduate and postgraduate students from an university in the south of China took part in this study. The recruit standard is the same as in study 1.3 participants were excluded due to incomplete data. Additionally, another 9 participants were excluded given that their reaction time was less than one standard deviation. Hence, in total of 133 valid results (50 males, 83 females; $M_{\text {age }}=21.14$, $\mathrm{SD}_{\text {age }}=2.39$ ) were analyzed. Further, we randomly divided participants into gain condition group $(\mathrm{N}=66)$ and loss condition group $(\mathrm{N}=67)$, each group were assigned to either gain or loss conditions of decision tasks.

\subsubsection{Measures and Procedure}

We adopted Newcomb and Harlow's (1986) Perceived Loss of Control Scale to measure perceived self-control. The three items of the scale were used to measure the general uncontrollable feelings toward life events. A higher score refers to a lower level of perceived self-control. Scores were ranging from 1 ("totally agree") to 6 ("totally disagree"). The Cronbach's alpha of this scale in this study is .716.

All participants completed the gambling game on PC computers by E-Prime (version 2.0) separately. Individuals were randomly divided into two groups, in which gain condition group were given hypothetical possibilities to win some money while loss condition group were given hypothetical possibilities to loss some money. Each participant received 36 trials in total, in which 8 were practice trials to help them understand the game rules and the operation. Also, participants were able to repeat the practice if needed. There was a small break be- 
tween practice trials and formal trials, the sequences of trials were random. Before each trial, there would be a red sign to remind participants to be focused on the screen and get ready for the task. 500 ms later, two choices would appear and participants needed to press the corresponding key of the preferred choice. In half of trails, the safe choices were presented at the left while the risky choices were presented at the right. In the other half, choices were presented in the opposite way. A question followed the decision-making task to score how difficult participants felt to make a decision. During the task, reaction time was also recorded. Those whose reaction time was extremely short would be regarded as half heartedness and had been excluded from our results (See Figure 2).

Afterwards, participants were required to finish UCLA Loneliness Scales and Perceived Loss of Control Scales on the paper. For the sake of avoiding participants to figure out the aim of our study, we assigned some other unrelated personality and cognition questions between the two scales, which takes about 10 minutes to fill. Finally, participants filled demography information form. One week later, participants received their results and our letter of thanks.

\subsection{Results}

First, we divided participants into low-loneliness group ( $\mathrm{N}=56, \mathrm{M}=16.30$, $\mathrm{SD}$ $=2.87$ ) high-loneliness group $(\mathrm{N}=77, \mathrm{M}=22.56, \mathrm{SD}=2.15)$, the significant UCLA score differences of two groups had been certificated $p<.01$. Besides, $t$ test suggested that the degree of loneliness were not different in both condition groups $p>.10$. Same as before, scores of post-task question were identical in all groups.

In both decision-making groups, participants with low-loneliness score prefer safer choices, the results were show in Figure 3. However, for participants who performed trials under gain condition, the difference between low-loneliness participants and high-loneliness was notable $(\mathrm{t}=2.70, p<.01, \mathrm{~d}=4.26)$ while the difference for those who performed trials under loss condition was not significant ( $\mathrm{t}=1.95, p=.06>.05, \mathrm{~d}=2.25)$, which again verified the results in study 1 . What is more, the main effect of loneliness on decision making performance had been retested via UNAVOVA, which suggested that loneliness would remarkably influence the general risk preference $\mathrm{F}(1,131)=12.08, p<.01, \eta^{2}$ $=.08$, indicates that loneliness is able to significantly predicts risk preference. However, same as before, the main effect was only notable in gain condition

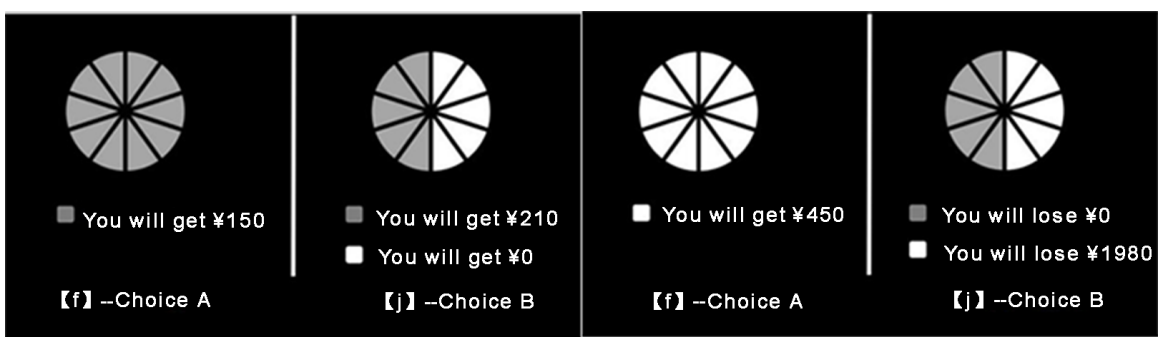

Figure 2. Sample screenshots of the decision-making in Study 2. 


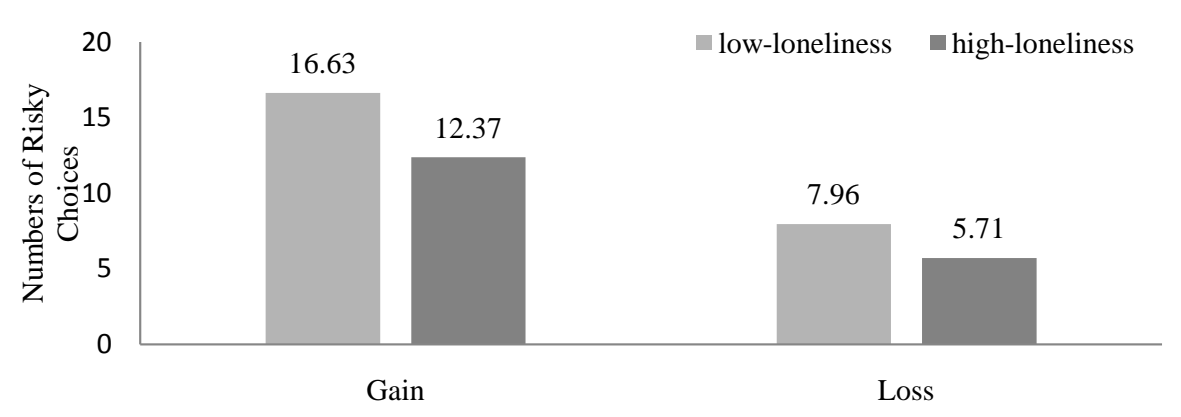

Figure 3. Risk preference of two groups in Study 2.

group, $\mathrm{F}(1,65)=7.12, p<.01, \eta^{2}=.10$ rather than in loss condition group $\mathrm{F}(1$, 64) $=3.33, p>.05, \eta^{2}=.05$.

Hence, we considered there might exist an interaction between loneliness and condition set (gain or loss scenario). So we conducted spotlight analysis to verify it based on Spiller et al. (2013). We set condition group (gain group $=0$; loss group $=1$ ), standardized UCLA scores and the interaction of the former variables as independent variables to conform regression analysis on risk preference. The results found a notable effect of interaction item on risk preference ( $\beta$ $=2.16, p<.05$ ). For individuals in gain group, the lonelier they are, the less risk they took, however, those in loss group were much less influenced by loneliness.

In addition, another hierarchical multiple regression analysis were conducted to check the relationships among loneliness, perceived loss of control and risk preference under gain condition, the results were presented in Table 1. We first set perceived loss of control scores as depended variable and found that UCLA scores was correlated to less perceived self-control $(\beta=.26, p<.01)$ as well as the number of risky choices $(\beta=-.34, p<.05)$. Moreover, the relationship between perceived self-control and risk preference under gain condition was also verified ( $\beta=-.83, p<.01)$. Nevertheless, once we combined loneliness, perceived loss of control together to predict risk preference, the significant correlation between loneliness and decision-making performance disappeared $(\beta=-.15, p>.05)$ but perceived control could still play as a predictor of risk choices $(\beta=-.72, p<.01)$, indicating the full mediation role of perceived self-control. The result is shown in Table 1.

Finally, bootstrap test was conformed followed Preacher \& Hayes's (2008) approach. The bootstrap estimates used in our study are based on 5000 bootstrap samples, with a 95\% Bias Corrected (BC) Confidence Intervals. The result re-examine the mediation role of perceived loss of control between loneliness and decision making (LLUC $=-.6311, \mathrm{ULCI}=-.0450$, with a BC 95\%).

\subsection{Discussion}

Study 2 again inspected the relationship between loneliness on risk preference under both conditions. A higher level of loneliness refers to less risky choices, consistent with our hypotheses that lonely individuals are more preventive in financial options. However this effect is only notable under gain condition, we 
Table 1. Regression analysis in Study 2.

\begin{tabular}{ccccccc}
\hline Variables & \multicolumn{2}{c}{ PLC } & \multicolumn{5}{c}{ PRG } \\
\hline & Model 1 & Model 2 & Model 3 & Model 4 & Model 5 & Model 6 \\
\hline Gender & .84 & .91 & -.98 & -1.07 & -.28 & -.41 \\
Age & -.12 & -.03 & .56 & .43 & .45 & .41 \\
Education & .10 & -.06 & 2.82 & 3.04 & 2.90 & 2.99 \\
Difficulty & -.25 & -.16 & -.36 & -.48 & -.57 & -.60 \\
UCLA & & $.26^{* *}$ & & $-.34^{*}$ & & -.15 \\
PLC & & & & & $-.83^{* *}$ & $-.72^{* *}$ \\
F & 1.64 & 7.14 & 4.94 & 5.16 & 6.80 & 5.82 \\
$\mathrm{R}^{2}$ & .05 & .22 & .14 & .17 & .21 & .22 \\
Adjusted R & .02 & .19 & .11 & .22 & .18 & .18 \\
\hline
\end{tabular}

Note: PLC means Perceived Loss of Control; PRG means risk preference under gain condition; Difficulty means how difficult participants felt during the task. ${ }^{\star}$ Significant at the $p=.05$ level. ${ }^{*}$ Significant at the $p$ $=.01$ level.

assume it is possibly because all participants became risky-evading under the loss condition in order to minimize more loss, that's why the difference between lonely group and non-lonely group was diminished. Apart from that, the mediation role of feelings in control had been examined as well.

\section{General Discussion}

The first purpose of our research is to verify the potential correlation between loneliness and financial risky decision making. To this end, two hundred and fifty participants finished gambling game via either pen-paper or PC and it appears that those who feel lonelier generally less likely to take risks, which is in line with our expectations. Basically, loners are more sensitive to fear-evoking cues as well as possible loss (Masi et al., 2013; Hawkley \& Cacioppo, 2010; Vohs, Baumeister, \& Chin, 2007), which lead them to a prevention focused mind-set (Lucas et al., 2010). For example, they prefer online relationships rather than in real because in order to minimize anxiety or they are less engaged in workplace due to over self-protection. However, most of previous research only paid attention to social events but neglected the possibility that the conservative mind-set might works on other conditions. Also, our findings supported Pieters' (2013) research that loners use the overreliance on material possessions as a coping strategy to fight against insecurity of unsatisfying social interactions (Pieters, 2013). As we can see from the two studies, although participants could not lose any money under the gain scenario, those in high-loneliness group were obviously more cautious-they were satisfied with less but certain money. Therefore, our results proved that the passive attitude of loners is able to go beyond social events and influence monetary decision making, illustrating that a loner would prefer to minimize loss rather than maximize benefit.

Moreover, to measure risk preference of participants, we set both gain and 
loss scenarios in 2 studies. Despite of the fact that under both scenarios, participants in high-loneliness group always took overall more conservative choices than those in low-loneliness group, the main effect of loneliness failed to reach significance in loss scenario. In other word, loners didn't behave notable differently under loss condition compare to non-loners. We assume conditions that leads to loss might sensitize the risk aversion, so that all participants became more risk evading regardless of the degree of loneliness. Nevertheless, given the scarce of prior discussion about loneliness and decision making, this finding need to be replicated and further explored.

Another purpose of our research is to examine the mediation role of perceived self-control between loneliness and decision making performance. It turns out participants with higher score in UCLA scales reported a loss of control feelings. As a result, contrary to those in low-loneliness group, high-loneliness participants might be over negative about the chances to get more money. Overall, loneliness would induce a combination of hyper vigilant state with loss of perceived control, resulting in the fact that lonely individuals focused more about avoiding loss rather than expecting reward under uncertainties.

Yet most of our findings are still preliminary and exploratory, the current paper provides novel insight into the research about decision making and loneliness. Up to now, a vast amount of studies discussed about lots of individual differences that may effects decision making performance. However, most of them only consider about a single dimension such as personality or cognitive styles. To our knowledge, the current research is the first to connect loneliness to risky decision making. Meanwhile, compare to overlapped attention to delve into the problematic reactions of loners in social events, we concern more about the behavioral tendencies of lonely individuals and hope to help them behave better in front of uncertainties. In addition, we make another contribution by examining through which bridge that loneliness influences risk preference in monetary decision task. Given the fact that perceived self-control works as an influential cognitive factor, the findings may suggest the possibility of other behavioral outcomes caused by loneliness.

\section{Limitations and Future Research}

Several shortcomings have to be taken into account with our results. We focused on decision making based on descriptions, however, it is necessary to replicate the findings with other paradigms refers to different kinds of uncertain conditions. Meanwhile, given that many studies demonstrated lonely people react differently from non-lonely people under pressure, it would be another research direction to take stress into account. Besides, another limitation to our design is that we only assessed the level of lonely feelings of participants instead of manipulating. However, loneliness is not able to be manipulated like other psychological factors such as emotions or aggression, which is a major impediment of relevant research. Hence, it is necessary for future scholars to come up with new operations. 


\section{Conclusion}

In summary, the current study verified that loneliness is able to lead to overall less risky choices in decision making tasks. However, the main effect is only significant when individuals are faced with potential benefit rather than loss. Moreover, perceived self-control is the pathway between loneliness and decision making under gain condition.

\section{References}

Bauer, M. A., Wilkie, J. E. B., Kim, J. K., \& Bodenhausen, G. V. (2012). Cuing Consumerism: Situational Materialism Undermines Personal and Social Well-Being. Psychological Science, 23, 517-523. https://doi.org/10.1177/0956797611429579

Baumeister, R. F., Twenge, J. M., \& Nuss, C. K. (2002). Effects of Social Exclusion on Cognitive Processes: Anticipated Aloneness Reduces Intelligent Thought. Journal of Personality and Social Psychology, 83, 817-827. https://doi.org/10.1037/0022-3514.83.4.817

Blanchette, I., \& Richards, A. (2010). The Influence of Affect on Higher Level Cognition: A Review of Research on Interpretation, Judgement, Decision Making and Reasoning. Cognition \& Emotion, 24, 37-41. https://doi.org/10.1080/02699930903132496

Buckert, M., Schwieren, C., Kudielka, B. M., \& Fiebach, C. J. (2014). Acute Stress Affects Risk Taking but Not Ambiguity Aversion. Frontiers in Neuroscience, 8, 1-11. https://doi.org/10.3389/fnins.2014.00082

Byrne, K. A., Silasi-Mansat, C. D., \& Worthy, D. A. (2015). Who Chokes under Pressure? The Big Five Personality Traits and Decision-Making under Pressure. Personality and Individual Differences, 74, 22-28. https://doi.org/10.1016/j.paid.2014.10.009

Cacioppo, J. T., \& Hawkley, L. C. (2009). Perceived Social Isolation and Cognition. Trends in Cognitive Sciences, 13, 447-454. https://doi.org/10.1016/j.tics.2009.06.005

Cacioppo, J. T., \& Patrick, W. (2008). Loneliness: Human Nature and the Need for Social Connection. New York: Norton.

Cassotti, M., Habib, M., Poirel, N., Aïte, A., Houdé, O., \& Moutier, S. (2012). Positive Emotional Context Eliminates the Framing Effect in Decision-Making. Emotion, 12, 926-931. https://doi.org/10.1037/a0026788

Cheung, E. O., \& Gardner, W. L. (2015). The Way I Make You Feel: Social Exclusion Enhances the Ability to Manage Others' Emotions. Journal of Experimental Social Psychology, 60, 59-75. https://doi.org/10.1016/j.jesp.2015.05.003

Clayton, R. B., Osborne, R. E., Miller, B. K., \& Oberle, C. D. (2013). Loneliness, Anxiousness, and Substance Use as Predictors of Facebook Use. Computers in Human Behavior, 29, 687-693. https://doi.org/10.1016/j.chb.2012.12.002

Cotten, S. R., Anderson, W. A., \& McCullough, B. M. (2013). Impact of Internet Use on Loneliness and Contact with Others among Older Adults: Cross-Sectional Analysis. Journal of Medical Internet Research, 15, 1-13. https://doi.org/10.2196/jmir.2306

De Martino, B., Camerer, C. F., \& Adolphs, R. (2010). Amygdala Damage Eliminates Monetary Loss Aversion. Proceedings of the National Academy of Sciences, 107, 3788-3792. https://doi.org/10.1073/pnas.0910230107

Derfler-Rozin, R., Pillutla, M., \& Thau, S. (2010). Social Reconnection Revisited: The Ef- 
fects of Social Exclusion Risk on Reciprocity, Trust, and General Risk-Taking. Organizational Behavior and Human Decision Processes, 112, 140-150.

https://doi.org/10.1016/j.obhdp.2010.02.005

Dohle, S., Keller, C., \& Siegrist, M. (2012). Fear and Anger: Antecedents and Consequences of Emotional Responses to Mobile Communication. Journal of Risk Research, 15, 435-446. https://doi.org/10.1080/13669877.2011.636835

Dohmen, T., Falk, A., Huffman, D., \& Sunde, U. (2010). Are Risk Aversion and Impatience Related to Cognitive Ability? American Economic Review, 100, 1238-1260. https://doi.org/10.1257/aer.100.3.1238

Greenaway, K. H., Storrs, K. R., Philipp, M. C., Louis, W. R., Hornsey, M. J., \& Vohs, K. D. (2015). Loss of Control Stimulates Approach Motivation. Journal of Experimental Social Psychology, 56, 235-241.

https://doi.org/10.1016/j.jesp.2014.10.009

Hawkley, L. C., \& Cacioppo, J. T. (2010). Loneliness Matters: A Theoretical and Empirical Review of Consequences and Mechanisms. Annals of Behavioral Medicine, 40, 218-227. https://doi.org/10.1007/s12160-010-9210-8

Heidemeier, H., \& Göritz, A. S. (2013). Perceived Control in Low-Control Circumstances: Control Beliefs Predict a Greater Decrease in Life Satisfaction Following Job Loss. Journal of Research in Personality, 47, 52-56.

https://doi.org/10.1016/j.jrp.2012.11.002

Heinrich, L. M., \& Gullone, E. (2006). The Clinical Significance of Loneliness: A Literature Review. Clinical Psychology Review, 26, 695-718. https://doi.org/10.1016/j.cpr.2006.04.002

Higgins, E. T. (1997). Beyond Pleasure and Pain. American Psychologist, 52, 1280-1300. https://doi.org/10.1037/0003-066X.52.12.1280

Jaremka, L. M., Peng, J., Bornstein, R., Alfano, C. M., Andridge, R. R., Povoski, S. P., Lipari, A. M., Agnese, D. M., Farrar, W. B., Yee, L. D., Carson, W. E., \& Kiecolt-Glaser, J. K. (2014). Cognitive Problems among Breast Cancer Survivors: Loneliness Enhances Risk. Psycho-Oncology, 23, 1356-1364. https://doi.org/10.1002/pon.3544

Kearns, A., Whitley, E., Tannahill, C., \& Ellaway, A. (2015). Loneliness, Social Relations and Health and Well-Being in Deprived Communities. Psychology, Health \& Medicine, 20, 332-344. https://doi.org/10.1080/13548506.2014.940354

Lakin, J. L., Chartrand, T. L., \& Arkin, R. M. (2008). I Am Too Just Like You. Psychological Science, 19, 816-822. https://doi.org/10.1111/j.1467-9280.2008.02162.x

Lam, L. W., \& Lau, D. C. (2012). Feeling Lonely at Work: Investigating the Consequences of Unsatisfactory Workplace Relationships. The International Journal of Human Resouce Management, 23, 1-18.

https://doi.org/10.1080/09585192.2012.665070

Lastovicka, J. L., \& Sirianni, N. J. (2011). Truly, Madly, Deeply: Consumers in the Throes of Material Possession Love. Journal of Consumer Research, 38, 323-342. https://doi.org/10.1086/658338

Lucas, G. M., Knowles, M. L., Gardner, W. L., Molden, D. C., \& Jefferis, V. E. (2010). Increasing Social Engagement among Lonely Individuals: The Role of Acceptance Cues and Promotion Motivations. Personality and Social Psychology Bulletin, 36, 1346-1359. https://doi.org/10.1177/0146167210382662

Martinez, F., Le Floch, V., Gaffié, B., \& Villejoubert, G. (2011). Reports of Wins and Risk Taking: An Investigation of the Mediating Effect of the Illusion of Control. Journal of Gambling Studies, 27, 271-285. 
https://doi.org/10.1007/s10899-010-9204-2

Masi, C. M., Chen, H. Y., Hawkley, L. C., \& Cacioppo, J. T. (2013). A Meta Analysis of Interventions to Reduce Loneliness. Personality and Social Psychological Review, 15, 219. https://doi.org/10.1177/1088868310377394.A

Newcomb, M., \& Harlow, L. (1986). Life Events and Substance Use among Adolescents: Mediating Effects of Perceived Loss of Control and Meaninglessness in Life. Journal of Personality and Social Psychology, 51, 564-577. https://doi.org/10.1037/0022-3514.51.3.564

Nordgren, L. F., Joop, V. D. P., \& Van Harreveld, F. (2007). Unpacking Perceived Control in Risk Perception: The Mediating Role of Anticipated Regret. Journal of Behavioral Decision Making, 20, 533-544. https://doi.org/10.1002/bdm.565

Otten, M., \& Jonas, K. J. (2013). Out of the Group, out of Control? The Brain Responds to Social Exclusion with Changes in Cognitive Control. Social Cognitive and Affective Neuroscience, 8, 789-794. https://doi.org/10.1093/scan/nss071

Peplau, L. A., \& Perlman, D. (1982). Perspectives on Loneliness. In L. A. Peplau, \& D. Perlman (Eds.), Loneliness: A Sourcebook of Current Theory, Research and Therapy (pp. 1-18). New York: Wiley.

Pieters, R. (2013). Bidirectional Dynamics of Materialism and Loneliness: Not Just a Vicious Cycle. Journal of Consumer Research, 40, 615-631. https://doi.org/10.1086/671564

Preacher, K. J., \& Hayes, A. F. (2008). Asymptotic and Resampling Strategies for Assessing and Comparing Indirect Effects in Multiple Mediator Models. Behavior Research Methods, 40, 879-891. http://doi.org/10.3758/BRM.40.3.879

Russell, D., Peplau, L. A., \& Cutrona, C. E. (1980). The Revised UCLA Loneliness Scale: Concurrent and Discriminant Validity Evidence. Journal of Personality and Social Psychology, 39, 472-480. https://doi.org/0022-3514/80/3903-0472

Sacco, D. F., Wirth, J. H., Hugenberg, K., Chen, Z., \& Williams, K. D. (2011). Theworld in Black and White: Ostracism Enhances the Categorical Perception of Social Information. Journal of Experimental Social Psychology, 47, 836-842. http://dx.doi.org/10.1016/j.jesp.2011.03.001

Saqib, N. U., \& Chan, E. Y. (2015). Time Pressure Reverses Risk Preferences. Organizational Behavior and Human Decision Processes, 130, 58-68. https://doi.org/10.1016/j.obhdp.2015.06.004

Sheldon, K. M., \& Kasser, T. (2008). Psychological Threat and Extrinsic Goal Striving. Motivation and Emotion, 32, 37-45. https://doi.org/10.1007/s11031-008-9081-5

Silva-Gómez, A. B., Rojas, D., Juárez, I., \& Flores, G. (2003). Decreased Dendritic Spine Density on Prefrontal Cortical and Hippocampal Pyramidal Neurons in Postweaning Social Isolation Rats. Brain Research, 983, 128-136. https://doi.org/10.1016/S0006-8993(03)03042-7

Skinner, E. A. (1996). A Guide to Constructs of Control. Journal of Personality and Social Psychology, 71, 549-570. https://doi.org/10.1037/0022-3514.71.3.549

Snyder, D. G. (2014). Hardnessing the Power of Loneliness: A Social Functional Approach to Loneliness at Work. Academy of Management Annual Meeting Proceedings, 1, 14066-14066. http://doi.org/10.5465/AMBPP.2014.14066abstract

Spiller, S. A., Fitzsimons, G. J., Lynch Jr, J. G., \& Maccelland, G. H. (2013). Sportlights, Floodlights and the Magic Number Zero: Simple Effects Tests in Moderated Regression. Journal of Marketing Research, 50, 277-288.

Sun, Y. C. (2011). The Impact of Locus of Control and Priming on the Endowment Effect. 
Scandinavian Journal of Psychology, 52, 420-426.

https://doi.org/10.1111/j.1467-9450.2011.00890.x

Teppers, E., Luyckx, K., Klimstra, T. A., \& Goossens, L. (2014). Loneliness and Facebook Motives in Adolescence: A Longitudinal Inquiry into Directionality of Effect. Journal of Adolescence, 37, 691-699. https://doi.org/10.1016/j.adolescence.2013.11.003

Trope, Y., Gervey, B., \& Bolger, N. (2003). The Role of Perceived Control in Overcoming Defensive Self-Evaluation. Journal of Experimental Social Psychology, 39, 407-419. https://doi.org/10.1016/S0022-1031(03)00035-0

Van Boven, L., Campbell, M. C., \& Gilovich, T. (2010). Stigmatizing Materialism: On Stereotypes and Impressions of Materialistic and Experiential Pursuits. Personality and Social Psychology Bulletin, 36, 551-563.

https://doi.org/10.1177/0146167210362790

Vohs, K. D., Baumeister, R. F., \& Chin, J. (2007). Feeling Duped: Emotional, Motivational, and Cognitive Aspects of Being Exploited by Others. Review of General Psychology, 11, 127-141. https://doi.org/10.1037/1089-2680.11.2.127

Wegier, P., \& Spaniol, J. (2015). The Effect of Time Pressure on Risky Financial Decisions from Description and Decisions from Experience. PLOS ONE, 10, 1-16.

https://doi.org/10.1371/journal.pone.0123740

Will, G. J., Van Lier, P. A. C., Crone, E. A., \& Güroğlu, B. (2016). Chronic Childhood Peer Rejection Is Associated with Heightened Neural Responses to Social Exclusion During Adolescence. Journal of Abnormal Child Psychology, 44, 43-55.

https://doi.org/10.1007/s10802-015-9983-0

Xiu, L., Kang, G., \& Roline, A. C. (2015). Who Negotiates a Higher Starting Salary? Nankai Business Review International, 6, 240-255. https://doi.org/10.1108/NBRI-01-2015-0004

Ye, Y., \& Lin, L. (2015). Examining Relations between Locus of Control, Loneliness, Subjective Well-Being, and Preference for Online Social Interaction. Psychological Reports, 116, 164-175. https://doi.org/10.2466/07.09.PR0.116k14w3

\section{Scientific Research Publishing}

Submit or recommend next manuscript to SCIRP and we will provide best service for you:

Accepting pre-submission inquiries through Email, Facebook, LinkedIn, Twitter, etc. A wide selection of journals (inclusive of 9 subjects, more than 200 journals)

Providing 24-hour high-quality service

User-friendly online submission system

Fair and swift peer-review system

Efficient typesetting and proofreading procedure

Display of the result of downloads and visits, as well as the number of cited articles

Maximum dissemination of your research work

Submit your manuscript at: http://papersubmission.scirp.org/

Or contact psych@scirp.org 